\title{
Em tempos de globalização e mudança: a identificação da cidadania na sociedade de informação
}

\author{
In times of globalization and change: the citizenship \\ identification in the information society
}

Rosemary PASSOS 1

Gildenir Carolino SANTOS

\section{R E S U M O}

As transformações proporcionadas pelo processo de globalização abrangem todos os segmentos que constituem uma sociedade, principalmente a sociedade atual regida pela busca de informações e construção do conhecimento, considerados como recursos necessários aos indivíduos para o seu estabelecimento profissional e sua interação social. A falta de uma qualificação e a desinformação, bem como a ausência da continuidade na formação profissional, são fortes argumentos para decretar a exclusão social e profissional dos indivíduos. Nessa perspectiva, observam-se mudanças de comportamentos profissionais e o estabelecimento de perfis profissionais compatíveis com a Sociedade da Informação. São perceptíveis as influências e os reflexos que a globalização exerce sobre o principal ator deste cenário, o ser humano, na sua busca incessante do pleno exercício de sua cidadania.

Palavras-chave: sociedade da informação, globalização, cidadania, profissional da informação, educação continuada.

\section{A B S T R A C T}

The transformations promoted by the globalization process, encompassed all segments constituting a society, mainly the current society driven by the

\footnotetext{
1 Bibliotecários, Faculdade de Educação, Universidade Estadual de Campinas. Rua Bertrand Russell, 801, Cidade Universitária, Caixa Postal, 6120, 13083-970, Campinas, SP, Brasil. Correspondência para/Correspondence to: R. PASSOS. E-mail: <bibrose@unicamp.br>.

Recebido em 16/10/2003 e aceito para publicação em 25/10/2004.
} 
information search and the construction of knowledge, both considered as necessary resources to the individuals for their proper professional establishment and social interaction. Lack of qualification and disinformation, as well as lack of continuity in the professional education, constitute strong arguments to determine the social and professional exclusion of the individuals. From this perspective, changes in professional behavior are observed, as well as the establishment of professional profiles compatible with the Information Society. Quite perceptible are the influences that the globalization exerts on the main actors of this scene, the human beings, and the consequences of it on them, while in their incessant search for the full exercise of citizenship.

Key words: information society, globalization, citizenship, information professional, continued education.

\section{N T R O D U Ç Ã O}

O fenômeno da globalização já se concretizou em nossa realidade social e econômica. A disseminação e o desenvolvimento de novas tecnologias são fatores determinantes, que possibilitam a expansão desse fenômeno. "Na sociedade global a moeda forte é a informação disponibilizada de forma universalmente acessível, 'just in time' " (JAMBEIRO, 1998, p.3).

Presencia-se diariamente as transformações decorrentes do processo globalização, que abrange todos os segmentos que constituem uma sociedade.

As mudanças daí decorrentes terão enorme impacto nos modos de aprender e fazer do ser humano. A revolução da informação poderá modificar de forma permanente a educação, o trabalho, o governo, os serviços públicos, o lazer, as formas de organizar a sociedade e, em última análise, a própria definição de entendimento humano. (JAMBEIRO, 1998, p.3).

A sociedade atual é considerada como a "sociedade do conhecimento, na qual o conhecimento é o principal recurso para os indivíduos e para a economia geral." Observa-se uma inversão nos valores sociais com relação às instituições conservadoras (sociedade, comunidade e família), que representam o alicerce e a estabilidade na formação dos indivíduos (DRUCKER, 1997, p.43).

O momento é da sociedade de organizações, e a organização moderna é desestabilizadora, objetivando exclusivamente a inovação.

Drucker (1997, p.44) faz uma breve reflexão sobre a organização social baseada no conhecimento, assinalando que:

[...] ela precisa ser organizada para mudanças constantes. A função da organização é colocar o conhecimento para trabalhar ferramentas, produtos e processos, na concepção do trabalho, no próprio conhecimento e que, por natureza muda rapidamente e as certezas de hoje se tornam os absurdos de amanhã.

Diante do contexto apresentado, não se pode alegar desconhecimento sobre o futuro que se apresenta; aliás, situações previstas a pouco tempo, já estão sendo vivenciadas. Os indivíduos são atropelados por informações, inovações, competições, tensões, e impelidos a buscar o conhecimento necessário à sua interação social.

A sociedade do conhecimento, ao contrário de padrões estabelecidos anteriormente, estabelece que deter a informação, possuir conhecimento especializado, não determina segurança e estabilidade: esse conhecimento deverá estar integrado a uma tarefa, pois segundo Drucker (1997, p.44) “[...] o 
conhecimento especializado por si só não produz nada".

Drucker (1997, p.45) ressalta que "[...] na sociedade de organizações, é seguro assumir que qualquer pessoa, com qualquer conhecimento, terá de adquirir novos conhecimentos a cada quatro ou cinco anos, sob pena de se tornar obsoleta".

Partindo desses pressupostos teóricos, busca-se estabelecer um referencial que demonstre os reflexos e as influências que a globalização, em alguns de seus aspectos culturais, econômicos, sociais, políticos, profissionais, tem exercido sobre o principal ator do cenário mundial, o ser humano.

Através da revisão de literatura, apresentam-se idéias de alguns autores, as quais permitem a discussão e contextualização do tema proposto: a globalização, a informação e a cidadania, serão assuntos tratados com enfoque direcionado para a preocupação com a preservação da identidade social de cada indivíduo, visto que, em tempos de globalização, os indivíduos são levados a desvincularem-se de sua própria linguagem, cultura, história ou até de sua localidade, para estarem inseridos num contexto que determinará sua sobrevivência.

A definição de papéis a serem desempenhados por cada indivíduo na sociedade atual, bem como o seu mercado de atuação, serão descritos de forma a estabelecer um panorama geral, sem a pretensão de apresentar soluções ou formas de procedimento, apenas como indicativos das atitudes e atividades que estão sendo estabelecidas como padrões para o profissional do conhecimento, ou de acordo com Drucker (1997), para "o trabalhador do conhecimento".

Jambeiro (1998, p.3) comenta que "a nova sociedade caminha para a multidisplinaridade, flexibilidade operacional, velocidade, precisão, pontualidade da informação. A humanidade está entrando na era da socialização da informação e da democratização de seu acesso".

A organização assume o papel da instituição principal na sociedade da informação; mas, independente do avanço das tecnologias de comunicação e informação, jamais devemos perder de vista o fato de que o ser humano, é o que mais conta, sendo decisivo o caráter de cada indivíduo, enquanto criador e protagonista da cultura.

\section{Globalização em questão}

A globalização é um fenômeno internacional, cujo "início" foi superficialmente "decretado" após a chamada Guerra Fria; entretanto, ao contrário dessa noção popular, trata-se de um processo antigo que tomou grandes proporções em nossos dias, neste "terceiro milênio".

A globalização, ou mundialização, de acordo com autores consultados, tem seus grandes aliados nas novas tecnologias de informação e comunicação. Através dessas novas tecnologias, "a informação desempenha um papel crescente na vida econômica, social, cultural e política" (MOORE, 1999, p.94).

O termo globalização recebe várias interpretações na literatura e observa-se a existência de certa precaução ao tentar estabelecer uma definição sobre globalização.

Beck (1999), demonstra um pouco dessa inquietação na abordagem de um significado que assume dimensões tão complexas:

Globalização é, com toda a certeza, a palavra mais usada e abusada e a menos definida dos últimos e dos próximos anos; é também a mais nebulosa e mal compreendida, e a de maior eficácia política. Como mostram os exemplos apresentados, é preciso distinguir (sem pretender uma exatidão ou completude absoluta) entre as diversas dimensões da globalização, a saber, a da comunicação técnica, a 
ecológica, a econômica, a da organização trabalhista, a cultural e a da sociedade civil etc. (BECK, 1999, p.39).

Globalização significa a experiência cotidiana da ação sem fronteiras nas dimensões da economia, da informação, da ecologia, da técnica, dos conflitos transculturais e da sociedade civil, e também o acolhimento de algo a um só tempo familiar, mas que não se traduza em um conceito, que é de difícil compreensão, mas que transforma o cotidiano com uma violência inegável e obriga todos a se acomodarem à sua presença e a fornecer respostas. (BECK, 1999, p.46).

Giddens (1990), citado por Vieira (1998, p.73), oferece ao termo globalização uma conotação estritamente social, referindo-se a um processo de "[...] intensificação de relações sociais em escala mundial que ligam localidades distantes de tal maneira, que acontecimentos locais são modelados por eventos ocorrendo a muitas milhas de distância e vice-versa."

Para outros, "a ideologia da globalização funciona, como conveniente cortina de fumaça. Os governos têm se servido da globalização para isentar-se de responsabilidade por tudo de negativo que acontece na economia" (BATISTA JÚNIOR, 1998, p.11); isto é, o desemprego, o aumento da concorrência na economia globalizada, as turbulências financeiras, são facilmente explicados quando associados a globalização. A realidade é que estamos diante de um fato concreto, tornando-se quase impossível atribuir à globalização um caráter único.

Em 1983, Theodore Levitt propõe este termo para designar a convergência de mercados no mundo inteiro. A globalização e a tecnologia seriam os dois principais fatores que moldavam as relações internacionais. (CORDELLIER, 1998, p.21).

De fato, a globalização aliada à tecnologia da informação e comunicação, permitiu amplo desenvolvimento no processo econômico internacional, fazendo com que a informação fosse utilizada como principal "recurso de poder" (ROCHA, 2000).

Numa economia de informação, a concorrência entre as organizações baseia-se em sua capacidade de adquirir, tratar, interpretar e utilizar a informação de forma eficaz. (McGEE; PRUSAK, 1994, p.3).

Partindo deste princípio, o acesso à informação se intensificou; constata-se visivelmente o crescimento da "indústria de informação", o que requer a criação de sistemas "provedores de conteúdo informativo", destinados ao gerenciamento, organização e tratamento do "produto informação" (MOORE, 1999, p.94).

\section{Informação: moeda da globalização}

O mundo globalizado tem na informação o seu "termômetro". Obter informações é prioridade, tanto nos países desenvolvidos, como nos em desenvolvimento, pelo fato de ser a informação o determinante principal para a construção de "sistemas sociais e econômicos".

De acordo com Moore (1999, p.94), a sociedade baseada na informação apresenta as seguintes características: utiliza a informação como recurso econômico; [nela], ocorre o maior uso da informação pelo público em geral; determina o desenvolvimento da informação na economia que tem como função satisfazer a demanda geral de meios e serviços de informação.

McGee e Prusak (1994, p.3), comentam que:

Embora a informação seja um ativo que precisa ser administrado, da mesma forma que os outros tipos de ativo representados pelos seres humanos, capital, propriedade e bens materiais, ela representa uma classe particular dentre esses outros tipos de ativo. 
As diferenças decorrem do próprio potencial da informação assim como do desafio de administrá-la ou gerenciá-la. A informação é infinitamente reutilizável, não se deteriora nem se deprecia, e seu valor é determinado exclusivamente pelo usuário; a fortuna de uns é a desgraça de outros.

Em relação a isso, Drucker (1993, p.179) salienta que, "informação são dados dotados de relevância e propósito". Portanto, para converter dados em informação é preciso conhecimento. E o conhecimento, por definição é especializado.

Com a facilidade de acesso à informação, criou-se a falsa impressão de que é possível adquirir-se todo e qualquer conhecimento, sem considerar-se a necessidade de obter-se a "informação correta, em tempo hábil, e no local adequado" (McGEE; PRUSAK, 1994, p.3).

Esses aspectos evidenciam a necessidade de gerenciamento informacional, pois verifica-se, claramente, a dificuldade de gerenciar-se o volume e a variedade de informações existentes, bem como a de criar mecanismos que acompanhem as rápidas transformações tecnológicas.

Uma boa gestão da informação exige que o pessoal compreenda o que é a informação, como pode ser obtida, tratada e empregada para tal e qual fim. (A SOCIEDADE..., 1999 p.94).

Neste cenário, as organizações investem na estruturação de sistemas de informação e de comunicação que possibilitem obterem-se dados informativos de forma rápida e eficiente. Os sistemas de informação permitem a comunicação entre pessoas sem necessidade de deslocamento, proporcionam a troca de informações em tempo real "online", favorecem a ligação entre profissionais com experiência multidisciplinar, aglomeram bancos de dados com facilidades específicas da organização (GALBRAITH; LAWLER, 1995).

O investimento apenas, em tecnologias de recuperação da informação, não é garantia de que uma organização esteja em condições de competir com o mercado global. O gerenciamento desses sistemas de informação deve obter respaldo em uma equipe constituída por pessoas dotadas de certas habilidades para o desenvolvimento de "núcleos de competência", onde a informação será tratada não só de forma a facilitar o acesso ao conhecimento, mas também, de forma a criar condições de construir o conhecimento.

\section{Adequação de perfis dos profissionais na sociedade da informação}

Os profissionais cotados para estar à frente de um sistema de informação gestor e gerador de conhecimentos, são os bibliotecários, documentalistas, analistas, arquivistas, cientistas da informação, editores etc.

$\mathrm{O}$ avanço tecnológico e o desenvolvimento das indústrias da informação, em geral, têm forte impacto sobre as profissões de informação [...]. Essas profissões são pressionadas por alguns fatores, como: aumento da tecnologia do trabalho da informação e o aumento na demanda dos serviços de informação, cada vez mais sofisticados e de alta qualidade.

Esses fatores exigem que os profissionais sejam mais qualificados, possuam além de conhecimento dos princípios em que se baseia o trabalho de informação, as competências técnicas exigidas para explorar plenamente o potencial tecnológico. Os profissionais da informação necessitam estar em contínua qualificação, que os possibilitem desenvolver $e$ aperfeiçoar suas habilidades. (A SOCIEDADE..., 1999, p.100).

A questão maior é que diante de uma sociedade baseada na busca incessante de informações, onde a globalização não impõe limites, tanto esses profissionais, como também 
aqueles não diretamente ligados ao trato com a informação - pois a tecnologia da informação atinge outras profissões -, têm de buscar aperfeiçoamento constante, para continuarem inseridos no mercado de trabalho.

Assim, Jambeiro (1998, p.3), diz que, a sociedade da informação ou sociedade global, proporciona o surgimento de novas funções tais, como:

monitoramento tecnológico; engenharia do conhecimento; documento técnico para certificações de qualidade; navegação dentro de recursos eletrônicos: participação e montagem de hipertextos e programas inteligentes, editoração eletrônica; gerenciamento e administração de múltiplas áreas de informação e comunicação.

É interessante observar o surgimento de uma nova categoria de profissional da informação, específico para o momento atual. Trata-se do "gestor de recursos informacionais", ou de acordo com a literatura levantada, denominado também "recuperador e analista de informação" ou "informata." (JAMBEIRO, 1998, p.4).

O "informata" é um profissional com o perfil de estrategista, com capacidade de compreender, analisar, criticar, captar e interpretar a realidade, em função do conhecimento disponível em suportes diversos de recuperação da informação, inclusive virtuais. Sua função consiste em tratar a informação sobre determinados temas, fazer análise dos conteúdos, realizar uma síntese para criar facilidades ao usuário final, colaborando assim, para o uso mais construtivo de informação.

O informata, como também é conhecido o profissional da informação, tem um papel importantíssimo nas organizações, "ele deverá saber o que cada um quer, como e quando, e também o que é relevante, de acordo com a estrutura da organização em que trabalhe, suas metas, objetivos, contexto no qual está envolvido e público a que serve" (JAMBEIRO, 1998, p.8).
Estamos diante de um "super profissional" e, para ser um informata, gestor de recursos informacionais, recuperador e analista de informação, quais são as exigências?

Em resposta a esta questão, Jambeiro (1998, p.7) lista algumas exigências. Segundo ele, esses profissionais deverão ser capazes de:

- exercitar visão crítica sobre a produção, distribuição e consumo de informação;

- analisar o conteúdo e dialogar com a fonte ou produtor e o consumidor sobre a qualidade de informação obtida e seu adequado tratamento;

- dominar dois níveis de linguagem: a terminologia da fonte, o produtor e a linguagem para comunicação com o público;

- combinar competência de gerenciamento e tratamento de informações como o domínio de usos das tecnologias de comunicação e eletrônica;

- valorizar o conhecimento sobre o ambiente em que vivem, buscando identificar possíveis facilidades e dificuldades ao exercício da missão;

- enfatizar o uso da informação como uma vantagem competitiva para o indivíduo e as organizações na sociedade;

- sinalizar necessidades de mudanças para a sociedade e particularmente para a comunidade social ou social ou organizacional em que vivem;

- reconhecer o valor econômico e político da informação.

Essas exigências, referem-se ao profissional da informação; entretanto, como a informação e a tecnologia têm influenciado outras profissões, estas também passaram a fazer as mesmas exigências. Atualmente, a falta de qualificação e a desinformação, bem como a falta de continuidade na formação profissional de qualquer cidadão, são fortes argumentos para decretarmos a exclusão do indivíduo do mercado 
de trabalho e, conseqüentemente, levá-lo à exclusão social.

\section{Cidadania e globalização na sociedade da informação}

Neste momento, do presente texto, é necessária uma pausa, para mudarmos o foco desta análise, mas observando-se que, nas entrelinhas, o foco no indivíduo e na sua participação na sociedade global da informação, do conhecimento, da tecnologia, de organizações, ou qual seja a denominação atribuída, esteve presente em cada item discutido nesse trabalho.

Fora do mundo dos negócios, a tecnologia da informação alterou as formas, processos e, com freqüência, nosso estilo de vida. No mundo desenvolvido, as crianças aprendem princípios de computação, na mais tenra infância, pois seus brinquedos muitas vezes são baseados nessa tecnologia. As pessoas interagem todos os dias com dezenas de dispositivos que contêm alguma forma de microprocessador. (McGEE; PRUSAK, 1994, p.5).

No cerne das transformações que estão alterando o panorama mundial, a informação é recurso de poder, pela vinculação do desenvolvimento com a capacidade de uma sociedade em gerar e aplicar conhecimentos. A informação concorre, assim, para o exercício da cidadania, à medida que possibilita ao indivíduo compreender a dimensão dessa mudança e oferece os meios de ação individual e coletiva de auto-ajustamento. Para isso, no entanto, é necessário garantir ao indivíduo o acesso à educação e à informação. (ROCHA, 2000, p.40).

As citações anteriores, trazem a lembrança, de que a informação está presente, nas situações mais rotineiras de nossas vidas, podemos encontrar tecnologia desde a cozinha de nossas casas, à caminho do trabalho, no trabalho, em escolas, hospitais etc. Estar informado atualmente é obrigação.

Do mesmo modo que utilizamos informação como consumidores de bens e serviços, devemos utilizá-la como cidadãos para exercer nossos direitos e nossas responsabilidades.

As tecnologias de disseminação de informação aceleraram o processo de globalização, antes que problemas sociais relacionados à educação, à saúde, etc., pudessem alcançar plena solução em países em desenvolvimento como o nosso.

Sabemos que os problemas de um país serão resolvidos apenas pela intervenção do Estado ou do mercado. É necessário um consenso que estabeleça condições básicas de cidadania, garantindo a liberdade do mercado e da competição econômica, para que não haja conflito entre esses dois interesses (ROCHA, 2000).

A 'revolução informática' que sacudiu as últimas duas décadas tampouco gerou benefícios de forma eqüitativa. Em que pese a expansão do acesso a computadores, à Internet, à televisão por cabo e a outras tecnologias comunicacionais, 2 bilhões de pessoas ainda não têm eletricidade e milhões de pessoas ainda não têm acesso ao telefone. A famosa 'sociedade do conhecimento' tampouco se traduziu em mais e melhores empregos, mas numa segmentação do mercado de trabalho. (SCHUGURENSKY, 2000, p.183).

Temos conhecimento de que os direitos fundamentais às pessoas (liberdade de expressão, direito de ser tratado como ser humano, religião e direito à proteção jurídica, e principalmente o direito a uma vida digna), muitas vezes não são plenamente exercidos.

Situação agravada em uma sociedade em que informação e conhecimento são fundamentais. "Os cidadãos mal informados 
vêem freqüentemente seus direitos negados, por falta dos meios necessários para fazê-los valer..." (A SOCIEDADE..., 1999, p.101).

O direito à informação não deve depender da capacidade financeira individual ou da habilidade em outras línguas, de seu nível de formação, nem de qualquer outro fator [...], que possa limitar sua capacidade de se informar. (A SOCIEDADE..., 1999, p.101).

Existe grande preocupação de que a sociedade de informação agrave as diferenças já existentes nas sociedades, entre "[...] ricos e pobres, maiorias e minorias étnicas, lingüísticas ou religiosas: entre as pessoas em plena posse de suas faculdades físicas e mentais e os deficientes" (A SOCIEDADE, 1999, p.105).

Outros autores também possuem uma visão não otimista da globalização em relação aos aspectos sociais, como se verifica nas afirmações de Drahos, Martin e Schuman, citados por Rocha (2000, p.42), alertando para:

[...] o risco de a globalização levar o mundo para uma sociedade de exclusão e desemprego - a 'sociedade 20 por 80 '. Ao mesmo tempo, enfatizam que o afastamento do modelo tradicional de desenvolvimento econômico não tem de, necessariamente levar à desagregação social, mas pode perfeitamente buscar novas formas de bem-estar, desde que se desenvolvam ações para o fortalecimento da sociedade civil.

Atrelados ao novo paradigma de sociedade, ainda encontramos as desigualdades de renda, distinção entre países e grupos sociais "ricos" e "pobres" em informação, as minorias excluídas, populações marginalizadas como desempregados crônicos, os "sem-teto" e outros, engrossando a larga fatia dos que ainda estão longe de serem integrados à nova sociedade do conhecimento (WERTHEIN, 2000).

Leal (1996), citado por Werthein (2000, p.73), aponta os defeitos éticos da sociedade da informação, relacionados às questões de múltiplas perdas:

\begin{abstract}
[...] perda da qualificação, associada à automação, e desemprego; da comunicação interpessoal e grupal, transformada pelas novas tecnologias ou mesmo destruída por elas; de privacidade, pela invasão de nosso espaço individual e efeitos da violência visual e poluição acústica; de controle sobre a vida pessoal e o mundo circulante; e do sentido de identidade, associado à profunda intimidação pela crescente complexidade tecnológica.
\end{abstract}

Várias ações estão sendo providenciadas para que o processo de globalização determinado pela tecnologia de informação e comunicação, ocorra de forma a estar provendo aos indivíduos o exercício pleno de sua cidadania.

Entre as ações providenciadas, Rocha (2000, p.44) cita alguns procedimentos tais como:

- oferecer um modelo educacional que priorize a questão da cidadania;

- oferecer maior eficiência no uso dos recursos públicos, com base na diversidade e interdisciplinaridade, multicultural;

- estabelecer parâmetros curriculares preocupados com a cultura regional e local;

- permitir aos jovens o acesso à tecnologia e preparando-os para o mercado de trabalho e para a cidadania.

Na releitura dos procedimentos citados, observa-se que os resultados serão relevantes, se houver maior investimento em educação e políticas sociais, o que nos levará em direção à sociedade mais justa e solidária.

\section{CONSIDERAÇÕ ES FIN A IS}

Ao tentar abordar a questão da cidadania no contexto globalizado, na sociedade de informação, observaram-se alguns aspectos 
importantes e essenciais na constituição dos indivíduos. O simples contato com a sociedade da informação, ou do conhecimento, no momento globalizado, não significa estar inserido em seu contexto.

O paradigma da sociedade da informação no contexto da globalização, tem levado os indivíduos a constantes transformações, tanto no que se refere à sua formação profissional e ao convívio social, como em suas atitudes pessoais. Independente da condição social, grau de instrução, ou condições econômicas, a globalização tem imposto a todos os indivíduos, novos posicionamentos:

Essa nova civilização traz consigo novos estilos de família; maneiras diferentes de trabalhar, amar e viver; uma nova economia; novos conflitos políticos; e acima de tudo uma consciência modificada. (ROCHA, 2000, p.42).

Nos indivíduos, impelidos pela agilidade oferecida no mercado, o espírito competitivo desperta a necessidade de buscar novas alternativas profissionais.

Estar no mercado globalizado exige, além da qualificação, estar em constante atualização profissional. A sociedade da informação determina o início de um novo modelo de sociedade que se forma paralelamente à outra, cujos problemas sociais, econômicos, políticos, continuam a existir, sem ao menos apresentar uma pequena estabilidade.

\section{REFERÊ N CIAS}

A SOCIEDADE da informação: ciência e tecnologia para a construção da Sociedade da Informação no Brasil. São Paulo: UNIEMP, 1999. p.94-105.

BATISTA JÚNIOR, P.N. Prefácio. In: HIRST, P.; THOMPSON, G. Globalização em questão: a economia internacional e as possibilidades de governabilidade. Petrópolis: Vozes, 1998. p.11.
Percebem-se duas dificuldades distintas: a do indivíduo que almeja sua estabilidade no momento globalizado, sujeito às pressões, e competições, ansioso para assimilar novas culturas e conhecimentos, e disposto a relegar sua própria história cultural para manter-se em condições de concorrer com o restante do mundo. Outra questão refere-se aos indivíduos que não conseguiram sequer serem inseridos na sociedade para exercer o mínimo de cidadania a que têm direito.

Direito à educação, direito à saúde, direito ao trabalho, direito à moradia com dignidade, acrescidos atualmente do direito de terem acesso à informação.

Ações governamentais, aliadas a ONG, têm observado essa questão, procurando sanar as dificuldades através de sistemas educacionais e serviços sociais, que são as instituições mais próximas ligadas aos direitos sociais.

Nos países em desenvolvimento, as transformações da sociedade para a sociedade da informação, deverão ocorrer ao mesmo tempo em que se busca diminuir as deficiências sociais existentes.

Nesse contexto, da sociedade organizada a "partir do paradigma do conhecimento" e da informação, o fator educação tem um papel fundamental, pois através dela é que se concretizará o "projeto da sociedade do conhecimento" capaz de promover a formação de indivíduos e garantir o pleno exercício da cidadania (ROCHA, 2000, p.43).

BECK, U. O que é globalização? Equívocos do globalismo respostas à globalização. São Paulo: Paz e Terra, 1999. p.39-47.

CORDELLIER, S. (Org.). A globalização para lá dos mitos. Lisboa: Bizêncio, 1998. p.21.

DRUCKER, P.F. Administrando em tempos de grandes mudanças. 4.ed. São Paulo: Pioneira. 1997. p.43-45. 
DRUCKER, P.F. As novas realidades: no governo, na política, na economia e nas empresas, na sociedade e na visão do mundo. 3.ed. São Paulo: Pioneira, 1993. p.179.

GALBRAITH, J.R.; LAWLER III, E.E. Organizando para competir no futuro. São Paulo: Makron Books, 1995.

JAMBEIRO, O. Gestão e tratamento da informação na sociedade tecnológica. São Paulo em Perspectiva, São Paulo, v.12, n.4, 1998. p.3-10.

McGEE, J.; PRUSAK, L. Gerenciamento estratégico da informação: aumente sua competitividade e a eficiência de sua empresa utilizando a informação como uma ferramenta estratégica. 6.ed. Rio de Janeiro: Campus, 1994. p.3-5.
MOORE, N. A sociedade da informação. In: A INFORMAÇÃO: tendências para o novo milênio. Brasília: IBICT, 1999. p.94-95.

ROCHA, M.P.C. A questão da cidadania na sociedade da informação. Ciência da Informação, Brasília, v.29, n.1, p.40-45, 2000.

SCHUGURENSKY, D. Globalização, democracia participativa e educação cidadã: o cruzamento da pedagogia e da política pública. In: SILVA, L.H. (Org.). Século XXI: qual conhecimento? Qual currículo? 2.ed. Rio de Janeiro: Vozes. 2000. p.183.

VIEIRA, L. Cidadania e globalização. 2.ed. Rio de Janeiro: Record, 1998, p.73.

WERTHEIN, J.A. A sociedade da informação e seus desafios. Ciência da Informação, Brasília, v.29, n.2, p.71-77, 2000. 